\title{
Palatopharyngeal Muscle Suspension Suture Technique for Obstructive Sleep Apnea
}

\author{
Dong Gyu Choi ${ }^{\mathbb{D}}$, Dong Woo Lee ${ }^{\mathbb{D}}$, Joo Yeon Kim ${ }^{\mathbb{D}}$, and Jae Hwan Kwon ${ }^{\mathbb{D}}$ \\ Department of Otolaryngology-Head and Neck Surgery, Kosin University College of Medicine, Busan, Korea
}

수면무호흡 환자 치료를 위한 구개인두근 현수봉합술기

최동규 · 이동우 · 김주연 · 권재환

고신대학교 의과대학 이비인후과학교실

\author{
Received August 19, 2021 \\ Revised October 12, 2021 \\ Accepted November 15, 2021 \\ Address for correspondence \\ Jae Hwan Kwon, MD, PhD \\ Department of Otolaryngology- \\ Head and Neck Surgery, \\ Kosin University \\ College of Medicine, \\ 262 Gamcheon-ro, Seo-gu, \\ Busan 49267, Korea \\ Tel $+82-51-990-6247$ \\ Fax $+82-51-990-3257$ \\ E-mail entkwon@hanmail.net
}

\begin{abstract}
Various treatment modalities for obstructive sleep apnea (OSA) patients were introduced including continuous positive airway pressure (CPAP), lifestyle modification, and surgery. Numerous factors such as compliance, treatment failure, and preference should be considered when deciding the treatment. In general, patients for whom CPAP or other conservative treatment modalities failed become candidates for surgical treatments. Uvulopalatopharyngoplasty is one of the most generally performed surgeries, of which success rate is relatively low. Recently, numerous techniques that can correct lateral pharyngeal obstruction for OSA patients were introduced. However, some of them are technically difficult and aggressive. In this article, we introduce a novel surgical method for OSA called palatopharyngeal muscle suspension suture technique. Korean J Otorhinolaryngol-Head Neck Surg 2022;65(1):66-70
\end{abstract}

\section{서 론}

폐쇄성 수면무호흡증(obstructive sleep apnea, OSA)은 반 복적인 야간 기도 폐쇄와 빈번한 수면 중단으로 인하여 심혈 관계 질환, 삶의 질 저하 및 수면 감소 등의 합병증이 발생하 는 흔한 질환이다. ${ }^{1,2)}$ 유병률은 남성의 약 $22 \%$, 여성의 $17 \%$ 로 보고되고 있다. ${ }^{3)}$ 폐쇄성 수면무호흡증의 치료는 생활습관교정, 지속성 기도양압호흡(continuous positive airway pressure, $\mathrm{CPAP}$, 구강 내 장치 및 수술적 치료 등의 방법이 있다. $\mathrm{CPAP}$ 는 폐쇄성 수면무호흡증의 효과적인 치료 방법이지만, 연구 에 따라 순응도가 $17 \%-54 \%$ 로 낮게 보고되고 있으며, CPAP 치료가 실패한 환자들에게는 다른 치료 방법이 필요하다.) $\mathrm{CPAP}$, 약물치료, 생활습관교정 등의 치료가 만족할만한 결
과를 얻지 못한 환자들은 수술적 치료가 대안이 될 수 있다.5) 기도 폐쇄 부위의 형태에 따른 다양한 수술적 치료가 고안되 었으며 술후 부작용을 줄이고 성공률을 높이는 여러 수술 방법이 소개되고 있다. ${ }^{6}$ 고식적인 방법으로 구개수구개인두 성형술(uvulopalatopharyngoplasty, UPPP)이 널리 시행되고 있으며, 최근 외측 인두벽 폐쇄를 교정하기 위해 lateral-expansion pharyngoplasty, expansion sphincter pharyngoplasty 등의 다양한 수술적 치료 방법이 고안되었으나, 기술 적으로 어렵고 침습적이며 시간이 오래 걸린다는 단점이 있 다. $^{7-9)}$ 본 논문에서는 폐쇄성 수면무호흡증을 치료하기 위한 구개수구개인두성형술 중 비교적 쉽게 시행 가능하고 최소 침습적 방법인 palatopharyngeal muscle suspension suture technique을 소개하고자 한다.

This is an Open Access article distributed under the terms of the Creative Commons Attribution Non-Commercial License (https://creativecommons.org/licenses/by-nc/4.0) which permits unrestricted non-commercial use, distribution, and reproduction in any medium, provided the original work is properly cited. 


\section{방 법}

수술 전 평가(Preoperative assessment)

수술 전 평가 과정에서 폐쇄성 수면무호흡증을 평가하는 일반적인 항목들에 대해서 평가를 시행하였다. 수면다원검사 (polysomnography, PSG), 약물유도수면내시경(drug-induced sleep endoscopy, DISE)을 통하여 수면의 질과 수면 시 폐쇄 가 발생하는 부위를 파악하였다. 그 외에도 체질량지수(body mass index), Brodsky 편도 분류법, 변형 Mallampati 척도를 확인하였다. PSG 검사 결과에서는 폐쇄성 수면무호흡과 관 련된 수치인 apnea-hypopnea index (AHI)와 respiratory disturbance index (RDI), lowest oxygen saturation (LSAT) 을 확인하여 수술 효과를 비교할 수 있도록 하였다. DISE를 통해서는 환자의 외측 인두부 폐쇄의 유무를 판단하였고, 가 장 주된 폐쇄 부위가 어디인지 파악할 수 있도록 시각화하는 것에 중점을 두며 평가를 시행하였다. ${ }^{10}$

수술 술기(Operative procedures)

앙와위 상태에서 전신마취와 기관 삽관을 시행하고 기관
내 튜브를 중앙으로 고정하였다. 이후 환자는 Rose 자세를 취 하고 Crowe-Davis 개구기(Medline, Northfield, IL, USA) 를 구강에 위치하여 구인두를 노출시켰다. 편도 겸자로 편도 를 내하측으로 잡아당기고 편도 상극을 전기소작기로 절개 한 후 조심스럽게 박리하여 편도 피막과 편도와 사이의 무혈 관성의 편평한 면을 따라 편도를 박리한 후, 양측 편도를 절 제하고 난 뒤 단극 전기소작기를 이용하여 전구개설궁 (anterior pillar)의 남은 부분의 일부를 위쪽 부위 경계면을 따 라 절제하였다(Fig. 1A). Monosyn 3-0 (B. Braun, Melsungen, Germany)을 구치후삼각(retromolar trigone) 부위에서 점막하로 통과시켜 편도와의 상측으로 나올 수 있도록 하였 다. 이후 편도와 바닥의 구개인두근(palatopharyngeus muscle)을 수직 방향으로 가능한 넓게 약 $2 \mathrm{~cm}$ 정도 걸고 나서 점막하를 통하여 처음 들어갔던 구치후삼각으로 나올 수 있 도록 하였다(Fig. 1B). 적당한 긴장을 유지한 채로 결찰을 시 행하였고, 구개부 조직이 전외상방으로 당겨지는 것을 확인 할 수 있었다(Fig. 1C). 마지막으로 Vicryl 4-0 (Ethicon Inc., Raritan, NJ, USA)을 사용하여 구개인두근과 구개설근(palatoglossus muscle)을 3-4회 정도 봉합하여 구개후부의 기

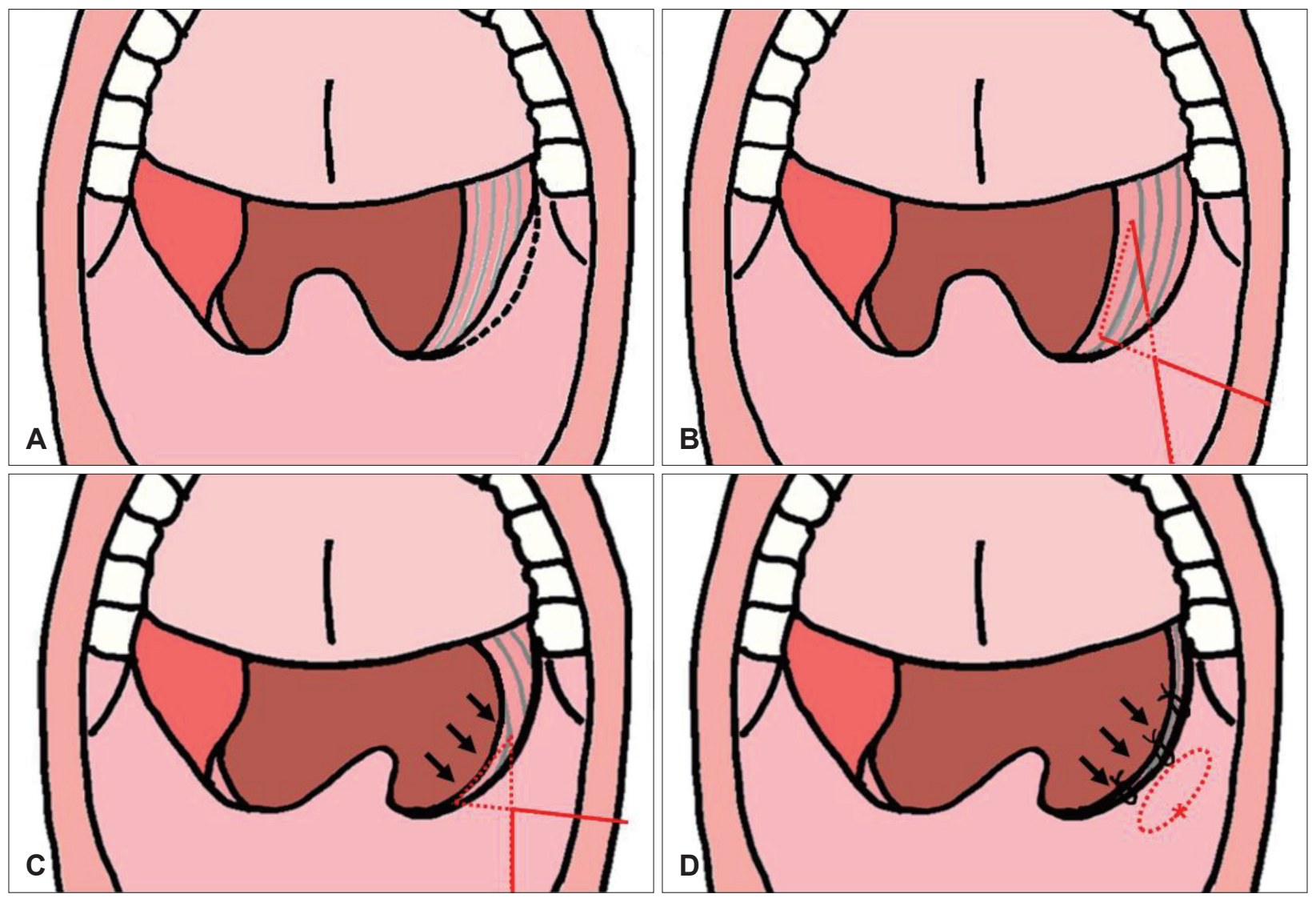

Fig. 1. Operation procedure illustrations. A: Right tonsillectomy was completed and part of anterior pillar mucosa resection was done. B: Suspension suture of palatopharyngeus muscle. C: Widening of lateral pharyngeal wall can be observed when tension is applied. D: Suture with Vicryl 4-0 (Ethicon Inc.) between palatopharyngeus muscle and palatoglossus muscle. 
도 확장을 위한 적당한 긴장을 유지할 수 있도록 하였다(Fig. 1D) (Supplementary Video 1).

\section{수술 후 관리(Postoperative care)}

수술 후 관리는 고식적인 구개수구개인두성형술을 시행한 환자와 다르지 않게 일반적인 수술 후 나타날 수 있는 통증 및 구역감, 변비 등의 증상에 대한 증상 조절을 시행하였다. 또한 수술 후에 발생 가능한 수술 부위 부종에 대한 평가 및 수술 부위 출혈 유무를 판단하기 위해서 주기적으로 후두내 시경을 촬영하였다. 환자는 수술 후 3일간 입원 치료를 받은 뒤 일상 생활이 가능하다고 판단되어 퇴원하였다. Palatopharyngeal muscle suspension suture에 사용하였던 monosyn은 mucosa 내부로 매몰되어 육안적으로 관찰되지 않았 고, 지속적인 긴장 유지를 위하여 봉합을 발사하지 않았다. 구개인두근과 구개설근을 봉합한 Vicryl 4-0도 흡수성 봉합 사로 자연스럽게 녹을 수 있도록 두었다.

\section{수술 후 결과(Postoperative result)}

수술 전 수면다원검사 결과 $\mathrm{AHI}$ 는 57.5 회/hr, RDI는 58.8

Table 1. Comparisons of preoperative and postoperative PSG findings

\begin{tabular}{lcc}
\hline \multicolumn{1}{c}{ PSG data } & Preoperative & Postoperative \\
\hline Total AHI (events/h) & 57.5 & 23.9 \\
RDI (events/h) & 58.8 & 26.0 \\
Supine AHI (events/h) & 82.8 & 26.0 \\
Lateral AHI (events/h) & 40.2 & 19.0 \\
LSAT (\%) & 79 & 88
\end{tabular}

PSG, polysomnography; RDI, respiratory disturbance index; AHI, apnea-hypopnea index; LSAT, lowest oxygen saturation

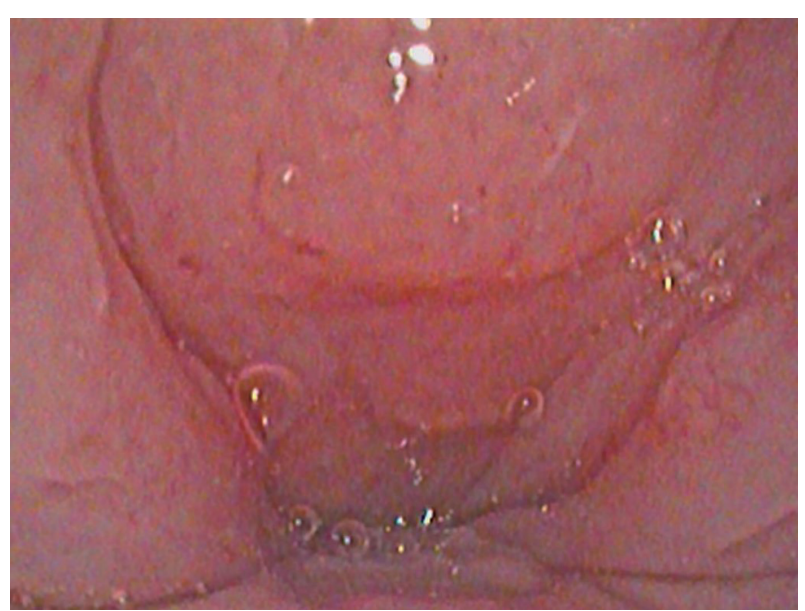

Fig. 2. Preoperative drug-induced sleep endoscopy. Complete concentric obstruction of uvula and lateral pharyngeal wall was identified. Snoring and apnea were present. 회/hr, LSAT는 79\%로 확인되었다(Table 1). 수술 전 약물유 도 수면내시경상에서는 구개수 및 외측 인두벽의 구심성 형태 의 완전한 폐쇄가 확인되었으며, 검사 시행 중 코골이 및 무 호흡을 확인할 수 있었다(Fig. 2). 수술 전 구강 내 내시경 소 견상 양측 편도의 비대, 설근부 비대와 함께 상대적으로 길고 두꺼운 구개수로 인한 기도의 협착이 관찰되었다(Fig. 3). 환 자는 수술 전 주관적인 증상으로 코막힘 및 코골이, 주간 졸 림증, 개운하지 못한 수면 및 불면, 피로감 등을 호소하였다. 수술 후 3개월 뒤에 수면다원검사, 약물유도 수면내시경 시행 및 증상 호전 유무에 대한 평가를 시행하였다. 수술 후 수면 다원검사 결과 AHI 23.9회/hr, RDI 26회/hr, LSAT 88\%로 대부분의 지표가 개선된 수치를 보였다(Table 1). 술후 약물 유도수면 내시경상 술전 검사와 비교해 구개수의 폐쇄는 확 인되지 않았으며 외측 인두벽의 미약한 구심성 형태의 폐쇄 가 있었다(Fig. 4). 주간 졸림증, 피로감 등 수술 전 느끼던 주 관적 증상 모두 호전되었다. 수술 후 구강 내 내시경 소견상 수술 전에 비해 비인두강이 많이 넓어진 것을 알 수 있었다 (Fig. 5). 술후 6개월째 비인두강 이물감 등의 합병증 없이 관 찰 중이다.

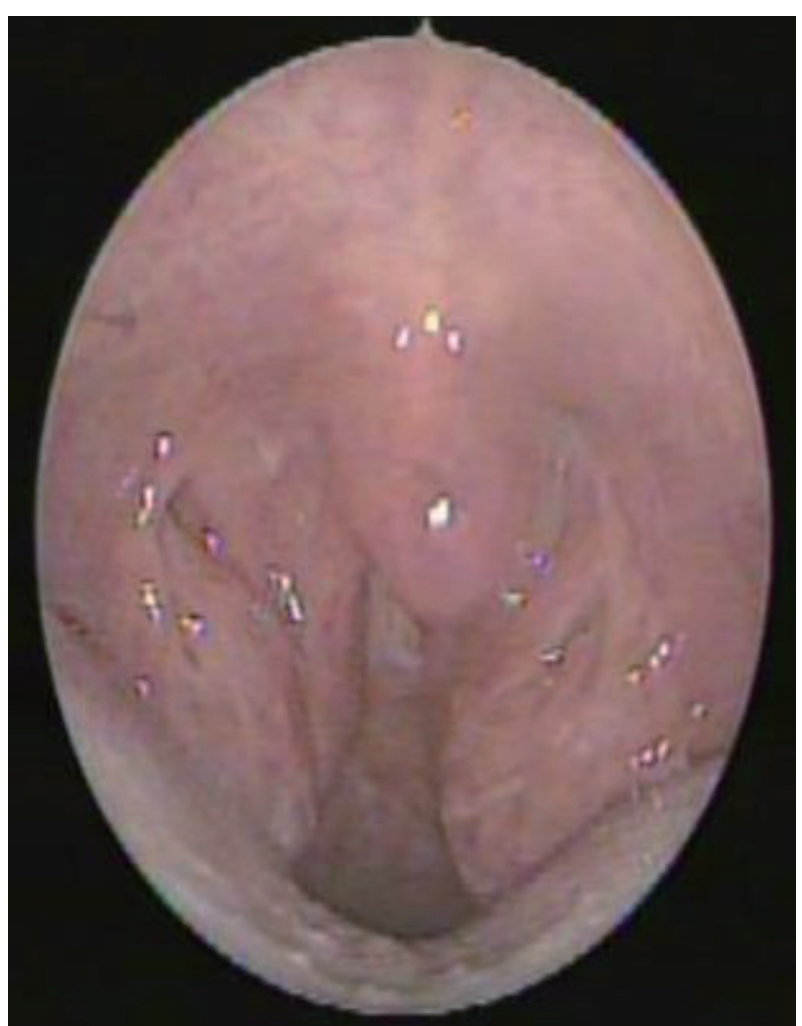

Fig. 3. Preoperative endoscopic finding. Bilateral palatine tonsillar hypertrophy, tongue base hypertrophy, elongation of uvula was observed. 


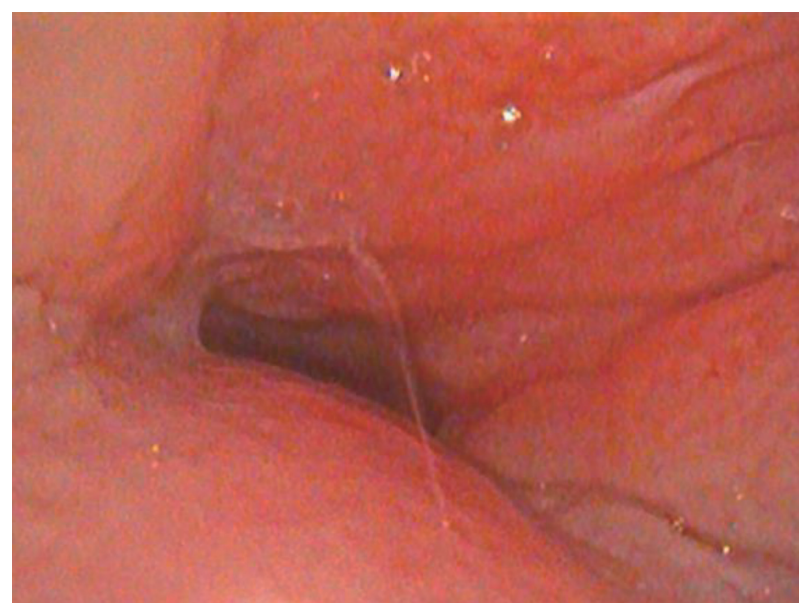

Fig. 4. Postoperative drug-induced sleep endoscopy. Relatively expanded airway with mild concentric obstruction of lateral pharyngeal wall was identified.

\section{결 과}

Lateral-expension pharyngoplasty는 상인두수축근(superior pharyngeal constrictor muscle)의 절제 및 회전을 포 함하여 구개피판을 Z-성형으로 넓혀주는 술식으로 정상 해 부학적 근육 구조물에 상당한 변형을 가하는 술식이다. 수면 다원검사 결과는 고식적인 UPPP보다 효과적이나 연하곤란, 구개인두기능부전(velopharyngeal insufficiency), 상처 벌어 짐 등의 부작용이 조금 더 발생하는 것으로 보고되었다." $\mathrm{Ex}^{-}$ pansion sphincter pharyngoplasty는 구개인두근의 하부의 일부분을 절제하여 근육을 이동시켜 전방, 상외측으로 돌리 는 술식이다. ${ }^{10}$

Single suspension suture는 구개인두근의 가장 상부 부위 에서 봉합을 시작하여 익돌구(pterygoid hamulus) 근처에서 구개설근을 통과하면서 편도와에서 봉합을 하여 긴장을 형 성하는 술식이다. ${ }^{11}$ 마찬가지로 pterygomandibular suspension suture는 익돌구 높이에서 익돌하악부(pterygomandibular) 가측에서 시작하여 후구개설궁(posterior pillar)를 통 과해서 구개인두근과 후구개설궁 피판을 걸고 익돌구 내측 으로 돌아와서 긴장을 형성하는 술식이다. ${ }^{12)}$

이러한 점에서 palatopharyngeal suspension suture는 $\mathrm{ex}^{-}$ pension phayrngoplasty와는 다르게 인두근육을 절제하거 나 회전하여 인두부를 확장하는 것이 아니라 비교적 덜 침습 적인 방법인 봉합사를 통해 긴장을 가한다. 따라서 정상 해부 학적 구조를 유지할 수 있으며, 부작용의 가능성도 낮을 것 으로 판단된다.

타 논문에서 소개하는 suspension suture 술식들과 본 논 문의 palatopharyngeal suspension suture와 유사한 점이 있

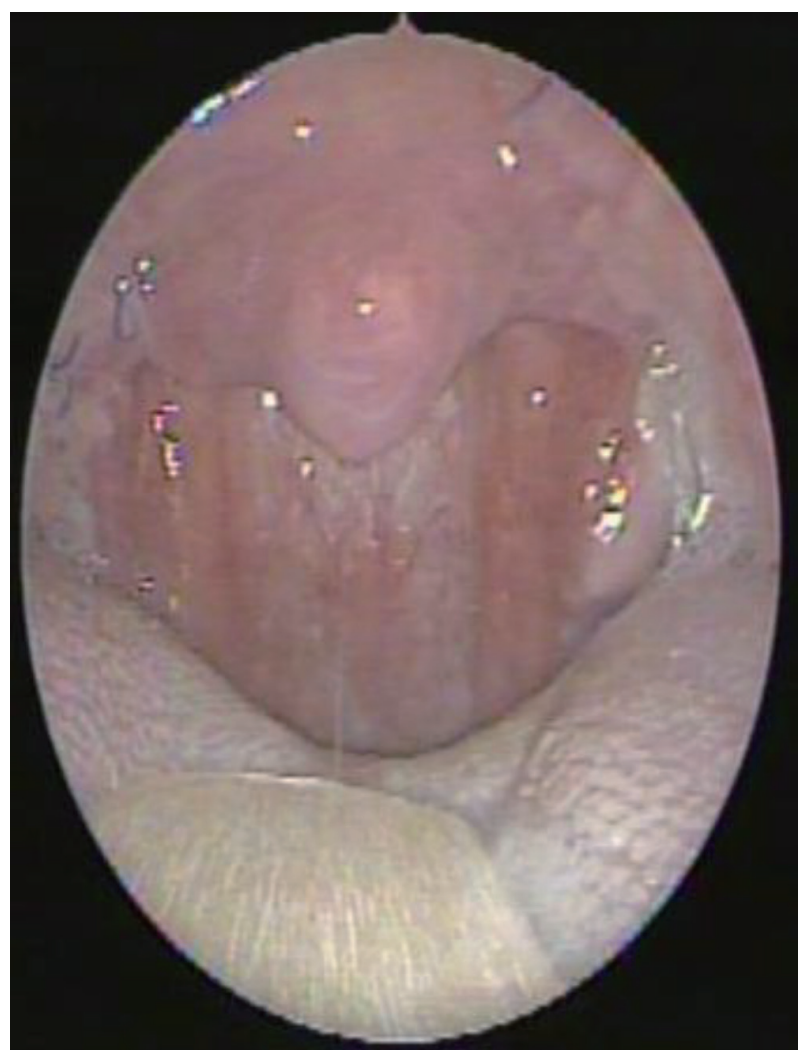

Fig. 5. Postoperative endoscopic finding. Compared with preoperative finding, pharyngeal cavity dilatation was recognized.

지만, 타 suspension suture는 구개인두근에 긴장도를 가하 는 지점이 하나의 점이라는 것을 가장 큰 차이점으로 볼 수 있다. Single suspension suture는 이와 같은 단점을 극복하 기 위해서 double suspension suture를 시행하여 처음 시행한 봉합 부위보다 외측하방 부위로 유사한 방식으로 한 번 더 봉합을 시행한다. ${ }^{13)}$ Palatopharyngeal suspension suture는 한 번의 봉합으로 구개인두근의 상부부터 하부까지 하나의 점이 아닌 전반적인 근육면(plane)으로 긴장도를 주면서 견인 할 수 있다는 장점이 있다(Fig. 1C). 이런 점에서 타 suspension suture보다 palatopharyngeal suspension suture는 구 개인두근에 긴장도를 더 넓게 줄 수 있으며, 술기의 시간도 단축할 수 있다.

결론적으로 본 연구에서 소개한 palatopharyngeal muscle suspension suture technique은 다른 술기에 비해 최소 침습 적이며, 술기가 어렵지 않아 초심자도 쉽고 빠르게 시행할 수 있고, 또한 가역적이라는 장점이 있다. 이에 저자들은 이 술 기가 폐쇄성 수면무호흡증의 술후 성공률을 높일 수 있는 추 가적인 술식 중의 하나가 될 것이라고 제안하는 바이다.

\section{Supplementary Video Legend}

Video 1. Palatopharyngeal muscle suspension suture technique. 


\section{Supplementary Materials}

The Data Supplement is available with this article at https://doi. org/10.3342/kjorl-hns.2021.00843.

\section{Acknowledgments}

None.

\section{Author Contribution}

Conceptualization: Jae Hwan Kwon. Data curation: Dong Woo Lee, Joo Yeon Kim. Supervision: Jae Hwan Kwon. Validation: Jae Hwan Kwon. Visualization: Dong Gyu Choi, Donw Woo Lee. Writing — original draft: Dong Gyu Choi. Writing_review \& editing: Joo Yeon Kim, Jae Hwan Kwon.

\section{ORCIDs}

Jae Hwan Kwon

Dong Gyu Choi

Dong Woo Lee

https://orcid.org/0000-0002-3260-6969

https://orcid.org/0000-0002-3632-7967

Joo Yeon Kim

https://orcid.org/0000-0002-4481-9339

https://orcid.org/0000-0001-8432-6056

\section{REFERENCES}

1) Chung S, Yoon IY, Shin YK, Lee CH, Kim JW, Ahn HJ. Endothelial dysfunction and inflammatory reactions of elderly and middle-aged men with obstructive sleep apnea syndrome. Sleep Breath 2009; 13(1):11-7.

2) Peppard PE, Young T, Barnet JH, Palta M, Hagen EW, Hla KM. Increased prevalence of sleep-disordered breathing in adults. Am J Epidemiol 2013;177(9):1006-14.

3) Franklin KA, Lindberg E. Obstructive sleep apnea is a common disorder in the population-a review on the epidemiology of sleep apnea. J Thorac Dis 2015;7(8):1311-22.

4) Weaver TE, Grunstein RR. Adherence to continuous positive airway pressure therapy: The challenge to effective treatment. Proc Am Thorac Soc 2008;5(2):173-8.

5) Tanna N, Smith BD, Zapanta PE, Karanetz I, Andrews BT, Urata MM, et al. Surgical management of obstructive sleep apnea. Plast Reconstr Surg 2016;137(4):1263-72.

6) Carvalho B, Hsia J, Capasso R. Surgical therapy of obstructive sleep apnea: A review. Neurotherapeutics 2012;9(4):710-6.

7) Hong SN, Kim HG, Han SY, Ji JY, Kim MK, Han DH, et al. Indications for and outcomes of expansion sphincter pharyngoplasty to treat lateral pharyngeal collapse in patients with obstructive sleep apnea. JAMA Otolaryngol Head Neck Surg 2019;145(5):405-12.

8) Cahali MB. Lateral pharyngoplasty: A new treatment for obstructive sleep apnea hypopnea syndrome. Laryngoscope 2003;113(11):1961-8.

9) Pang KP, Woodson BT. Expansion sphincter pharyngoplasty: A new technique for the treatment of obstructive sleep apnea. Otolaryngol Head Neck Surg 2007;137(1):110-4.

10) Oh MS, Dedhia RC. Current techniques and role of drug-induced sleep endoscopy for obstructive sleep apnea. Curr Sleep Medicine Rep 2017;3:152-63.

11) El-Ahl MA, El-Anwar MW. Expansion pharyngoplasty by new simple suspension sutures without tonsillectomy. Otolaryngol Head Neck Surg 2016;155(6):1065-8.

12) Lu YT, Tai SK, Lee TL. Pterygomandibular suspension suture: A simple modification of uvulopalatopharyngoplasty for severe obstructive sleep apnea. Eur Arch Otorhinolaryngol 2018;275(1):26973.

13) Askar SM, El-Anwar MW. Double suspension sutures: A simple surgical technique for selected cases of obstructive sleep apnoea: Our experience with twenty-two patients. Clin Otolaryngol 2018; 43(2):753-7. 